\title{
La tuberculosis y sus epónimos. Charles Mantoux (1877-1947)
}

\author{
J S Mazana
}

CP Tenerife. Médico del Cuerpo Facultativo de Sanidad Penitenciaria

\section{RESUMEN}

En 1908, un médico francés, Charles Mantoux, puso a punto un test para el diagnóstico de los contactos tuberculosos (infección tuberculosa latente). Este trabajo repasa datos históricos de esta técnica, tan relacionada con la simbología y mitología de la tuberculosis, la que en un tiempo fue llamada la peste blanca.

Palabras clave: Tuberculosis, test de la Tuberculina, Microbiología, Historia.

\section{TUBERCULOSIS AND ITS EPONYMS: CHARLES MANTOUX (1877-1947)}

\section{ABSTRACT}

In 1908, Charles Mantoux, a French doctor perfected a test for the diagnosis of tuberculosis contact (latent tuberculosis). This study reviews the history of this technique, which is closely linked to the symbolism and mythology of an illness that at one time was known as the white plague.

Key words: Tuberculosis, Tuberculin test, Microbiology, History.

Texto recibido: Septiembre 2008

Texto aceptado: Enero 2009

\section{CHARLES MANTOUX Y SU \\ INTRADERMORREACCIÓN \\ TUBERCULÍNICA HACE UN SIGLO}

En 1908, un médico francés, Charles Mantoux, puso a punto un test para el diagnóstico de los contactos tuberculosos (infección tuberculosa latente), que aun hoy se emplea rutinariamente. Sin embargo, esta prueba es poco sensible y específica por lo que tiene escaso valor diagnóstico en la tuberculosis activa. Es especialmente útil en los niños sospechosos y en los contactos estrechos de enfermos bacilíferos. No es recomendable implementar el test de Mantoux en el caso de una población de bajo riesgo pues aquí presenta una elevada tasa de falsos positivos. El desconocimiento de este personaje, la vigencia de esta técnica antituberculínica y la simbología y mitología que rodean a la peste blanca, justifican este esfuerzo. Existen otras efemérides de alcance o significación histó-

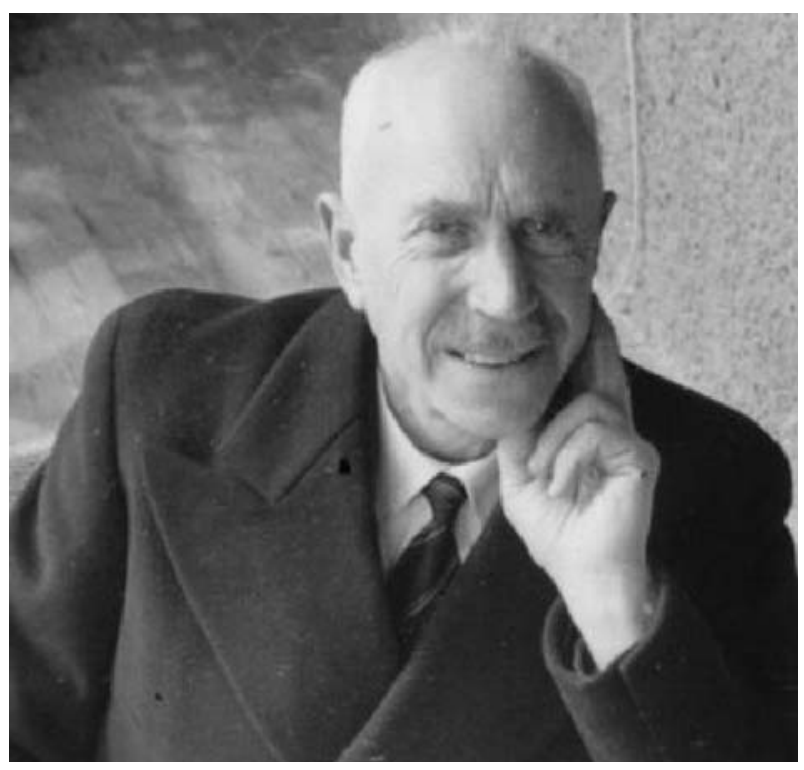

Charles Mantoux. 
rica correspondientes a 1908 de las que se han cumplido asimismo un siglo y que resultan interesantes de recordar en relación con la tuberculosis (Tabla I).

\section{Efemérides de 1908 relacionadas con la tuberculosis ${ }^{1}$}

Se celebra en Washington DC el VI Congreso Internacional de Tuberculosis que estimula el nacimiento de asociaciones y la creación de sanatorios antituberculosos en número de 148 en USA (la mayoría privados).

La ciudad de Chicago adopta la pasteurización obligatoria de la leche.

Julios Uhlenhuth y Xylander introducen el método de la antiformina para la concentración del esputo.

Albert Calmette y Camille Guérin desarrollan una cepa atenuada avirulenta del bacilo tuberculoso bovino, la conocida BCG, tras 13 años y 230 pases en un medio con papa y bilis glicerinado al $5 \%$.

P. H. Römer lleva a cabo estudios pioneros sobre la inmunidad en la tuberculosis.

Michel Chauvet describe el ápex pulmonar como una "zona de alarma” en el inicio de la tuberculosis pulmonar.

Ernst Moro desarrolló la prueba percutánea con lanolina y tuberculina al $50 \%$, más tarde conocida como test de la Dermotubina de Löwenstein.

Tabla I. El año 1908 pródigo en efemérides biomédicas.

En el campo de la Biomedicina, en el pasado año 1908 destacan también algunos hechos sobresalientes. Así, por ejemplo, Sir Archibald Edward Garrod describe los primeros errores congénitos del metabolismo (inborn errors of metabolism) aunque sus trabajos pioneros en genética de las enfermedades humanas no serán conocidos hasta 1940. Nace la genética de poblaciones gracias a Godfrey Harold Hardy, un matemático de Cambridge, y a Wilhelm Weinberg, un médico de Stuttgart, que establecen un teorema matemático que calcula las frecuencias genotípicas en una población en equilibrio, en ausencia de la presión selectiva y del efecto mutacional (ley de Hardy-Weinberg). En Alemania el denominado "coche de doctor”, un Opel 4/8 CV, sustituye al clásico coche de caballos. El catedrático de química médica en la Universidad de Praga, Richard von Zeynek, pone a punto la diatermia, una forma de electroterapia que él bautizó como "termopenetración", lo que fue posible gracias a la fabricación del primer transformador de alta frecuencia desarrollado en 1891 por un genio de la física, el neoyorquino Nikola Tesla, y a las teorías del fisicoquímico alemán Walter Nernst. El urólogo austriaco Leo Buerger describe la tromboangeítis obliterante, una vasculitis sistémica necrotizante. Se funda en Colonia la Sociedad Alemana de Ortodoncia y en Alton, Gran Bretaña, se crea la primera institución exclusiva para enfermos con tuberculosis ósea y articular, el Cripple's Home and Hospital dirigida por Henry Gauvain. En Namibia, colonia alemana, un antropólogo alemán de Friburgo llamado Eugen Fischer, defiende la "inferioridad" de la raza negra y la "degeneración” racial con el mestizaje, prohibiéndose los matrimonios entre blancos y negros, representando un acérrimo exponente del racismo antropológico imperante. Finalmente, también en 1908 Bernhard Dernburg, alto cargo del Reich, incentiva el desarrollo de la Medicina tropical en las colonias alemanas, fundamentalmente dirigido a la prevención y el tratamiento de las enfermedades infecciosas ${ }^{2}$.

El premio Nobel de Medicina y Fisiología de 1908 fue para el ruso Iliá IIlich Mechnikov y el alemán Paul Ehrlich. Metchnikoff fue un destacado inmunólogo que elaboró su teoría inmunitaria de la fagocitosis, un mecanismo de defensa inespecífico filogenéticamente muy antiguo. Considerado el "padre de la microbiología rusa”, sus investigaciones sobre la lúes fueron originales pero poco se sabe sobre su aportación al conocimiento de la tuberculosis, en parte quizá porque apenas publicó sobre la tisis ${ }^{3-5}$.

Preocupado en hallar un tratamiento eficaz para debilitar el escudo de cera de los bacilos de la tuberculosis (los lípidos constituyen el $40 \%$ de su peso seco) y aumentar la actividad fagocitaria de las células

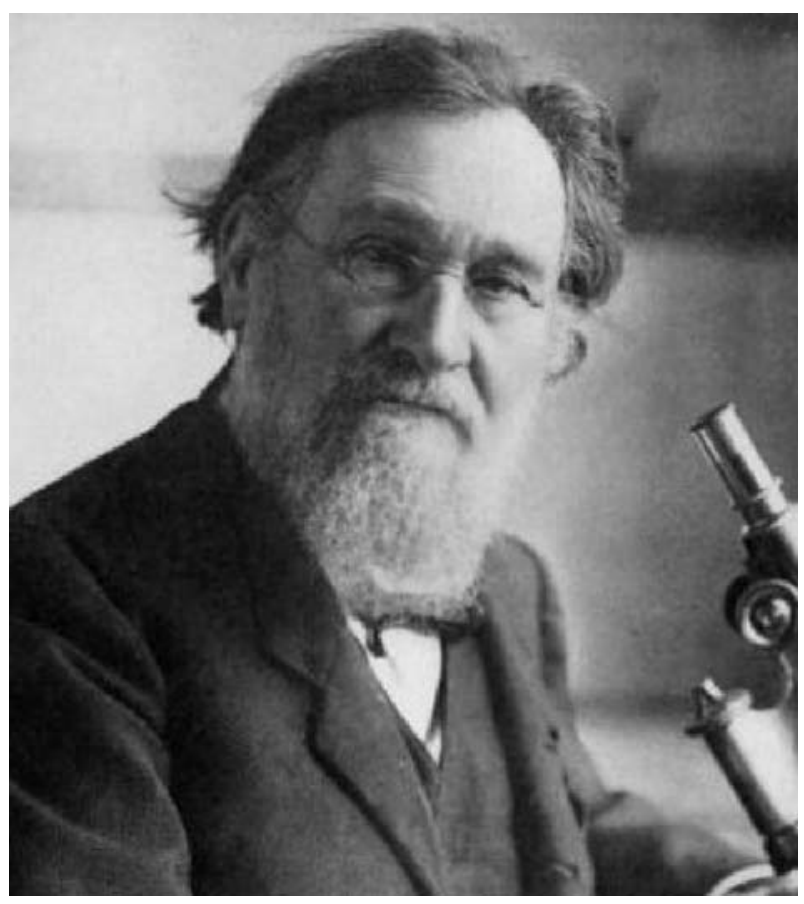

Iliá IIlich Mechnikov. 
gigantes, en el archivo de la Academia de Ciencias de Rusia se conservan algunos de sus cuadernos con anotaciones manuscritas originales sobre los protocolos que siguió en los experimentos con fermentos digestivos de las crisálidas de polilla $a^{6}$. Es curioso observar en este sentido cómo antes del descubrimiento de Koch del agente etiológico de la tuberculosis, el tratamiento de esta espantosa enfermedad se dirigía a detener la consunción orgánica, para lo cual se recurría a determinados climas, alimentos y ejercicios. Plinio el Viejo en su obra Historia Natural, señala algunas dietas: "Un hígado de lobo, hervido en vino leve; el tocino de una cerda alimentada con hierbas..." Se recurrió a otros tratamientos sin éxito, por citar sólo algunos: el hidrógeno sulfurado, los vapores de ácido fluorhídrico, la cura alcohólica de Leudet, los vapores de alquitrán, la creosota, el aceite de hígado de bacalao, el arsénico, el fósforo, los hipofosfitos y las inyecciones subcutáneas de yema de huevo mezclada con agua salada al 7 por mil (v/v). Pero desde antiguo lo que gozó de mayor predicamento fue la leche de vaca, de cabra, de camello, de burra, de elefante y, sobre todo la leche de mujer. Así, en el siglo XVI el médico holandés Petrus Forestus Almarianus aconsejaba a sus pacientes que mamasen de una hembra joven, ubicándose a los costados de ella, para permitir una succión continua. En este mismo sentido, también se consideraba beneficioso beber sangre de toro o de tortuga aunque confieso que desconozco el fundamento científico de tales prácticas dietéticas. Como vemos una enfermedad, la tuberculosis, rodeaba de un halo de misterio y superstición. En cuanto al clima, debe elegirse la alta montaña, pero también existían disponibles en el arsenal terapéutico antifímico inhalaciones específicas y más concentradas, como las de humo obtenido al quemar estiércol de vaca (Plinio), de algas marinas (Laennec), y el humo de resina o de brea $^{7}$. El clima de altura se complementaba con una dieta muy abundante que incluía numerosas comidas diarias, como lo describe minuciosa y elegantemente Thomas Mann en Der Zauberberg. Entre los ejercicios, Thomas Sydenham ("el Hipócrates inglés") propugnaba en 1742 montar a caballo diariamente. El filósofo y médico inglés John Locke, padre del empirismo, practicaba con este fin la equitación y murió de tuberculosis. La tuberculosis representa quizá la enfermedad infecciosa que más ha atraído a investigadores y curiosos a lo largo de la historia de la $\mathrm{Hu}-$ manidad por ser el prototipo de contagiosidad mór$\operatorname{bida}^{8} \mathrm{y}$ a que algunos personajes célebres murieron de tuberculosis como el rey Luis XIII (1643), Baruch Spinoza (1677), John Keats (1821), René T. H. Laennec, inventor del estetoscopio (1826), Marie Duples- sis (1847), Fréderic Chopin (1849), Charlotte Brontë (1855), George Orwell (1950), Eleanor Roosevelt (1962) y Vivien Leigh (1967).

\section{BOSQUEJO BIOGRÁFICO DE CHARLES MANTOUX}

Médico francés, nacido el 14 de mayo de 1877 y fallecido en París en 1947. Estudió Medicina en la Universidad de París siendo discípulo de Pierre Paul Broca (1824-1880) -uno de los fundadores de la moderna cirugía del cerebro- y del conocido patólogo y pediatra Víctor-Henri Hutinel (1849-1933). En 1904 se licenció en medicina por la Universidad de París, obtuvo el grado de doctor y se especializó en enfermedades venéreas, especialmente en la sífilis.



En su época de estudiante, Mantoux contrajo la tuberculosis sufriendo recaídas en los años siguientes. $\mathrm{Su}$ mala salud le impidió presentarse a una plaza de especialista en enfermedades venéreas convocada por una clínica y abandonó París. Comenzó a trabajar entonces en un sanatorio del sur del país, en Hyères, donde tuvo su primer encuentro con la temible tisis. Tras haber "probado el sabor de la tisis" como apunta su biógrafo Bezançon, se estableció en Cannes trabajando en un sanatorio antituberculoso, lo que le permitió com- 
patibilizar esta ocupación con su ejercicio profesional en París al disfrutar de largos periodos de vacaciones. De esta forma no perdió el contacto con el ambiente científico de la capital del Sena. Durante las vacaciones de primavera y verano permanece vinculado al Instituto Pasteur y a diversas clínicas parisinas, y se relaciona con directores de importantes clínicas de Francia. Por su delicada salud fue excluido del servicio militar, si bien en 1914 se alistó voluntario en el ejército contrayendo en el frente fiebres recurrentes (en el artículo original del ruso traducido, Vinnikov PL, Gerovits GA Charles Mantoux. Klin Med (Mosk). 1973 Mar; 51 (3): 144-6, la expresión забалел вазбратным тифом significa literalmente contrajo tifus recurrente, pero los diccionarios la traducen como fiebres recurrentes, que es la que se ha elegido. N. del T.), por lo cual es expulsado del ejército. Cuando mejoró su salud, Mantoux aceptó la honorable propuesta del patriarca de la tisioterapia francesa, el profesor Léon Bernard, para sustituirlo como interino en la clínica Laennec de especialidades. Al finalizar la Primera Guerra Mundial, regresó a Cannes donde compatibiliza su trabajo práctico con una serie de investigaciones clínico-científicas. En los veranos acude a los Alpes franceses donde se dedica al tratamiento de enfermos tuberculosos. El hijo mayor de Mantoux, médico como su padre, el doctor Gerard Mantoux, retrataba a su padre como "un hombre muy bondadoso, inteligente, franco, completamente entregado a su familia". En su tiempo libre, sus pasatiempos favoritos eran pasear y leer. Le encantaba viajar, sobre todo a España y a Italia, y recorrió toda Francia. En 1939 durante la invasión fascista de Francia, Mantoux contando 60 años de edad y con una salud quebradiza, volvió a enrolarse y partió al frente. Tras la capitulación de Francia regresó de nuevo a la práctica de la medicina. La familia Mantoux se distinguió por su marcado patriotismo. Su hijo menor, tras cruzar España clandestinamente, llegó a Marruecos ingresando en las Fuerzas Aéreas de Francia. Unos meses antes del final de la contienda, el alférez Mantoux, de 26 años, moría en acto de servicio a bordo de un bombardero. La muerte de su amado hijo le afectó mucho mermando aun más su salud y en la primavera de 1947, con 68 años, falleció Charles Mantoux. Bezançon escribe que "el final de la vida de Mantoux estuvo lleno de sufrimiento y amargura".

\section{SU PRUEBA INTRADÉRMICA}

Según testimonio del doctor Gerard Mantoux (hijo de nuestro biografiado) y de Bezançon, especialista francés en tuberculosis y amigo íntimo de la fami- lia Mantoux, Charles Mantoux no estaba del todo convencido de los resultados de la prueba de Pirquet (escarificación), dado que en algunos enfermos de tuberculosis la prueba daba negativa. En 1907 el pediatra austríaco Clemens Freiherr von Pirquet (18741929) sustituyó esta inyección subcutánea por una escarificación, aunque ya en 1903 Kligmuller la había hecho intradérmica. Los estudios de Mantoux sobre la tuberculosis le permitieron desarrollar un método diagnóstico de despistaje (screening) de tuberculosis en el ganado vacuno que más tarde ensayaría en cerdos y caballos. Del mismo modo, Mantoux llevó a cabo estudios experimentales en cobayas para valorar la reacción de hipersensibilidad a la tuberculina. Igualmente implementó estudios radiológicos en tuberculosis y publicó artículos sobre pleuritis y fiebre en enfermos tuberculosos. Fue pionero en el empleo del neumotórax artificial con fines terapéuticos sin disponer para ello de demasiados recursos financieros ${ }^{9,10}$.

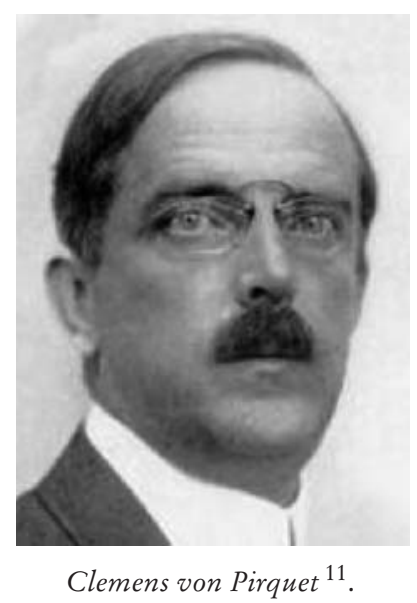

El 26-X-1907, en el congreso de la Sociedad Biológica de Francia, comunicó junto con el gran pediatra francés Pierre Nobecourt, que en el experimento de la tuberculosis con conejos había una serie de casos en que la reacción cutánea fue negativa, pero la prueba ocular fue positiva. Estas observaciones mostraron un cierto grado de inexactitud de los resultados de la reacción de Pirquet. Una comunicación del pediatra alemán Theodor Escherich (Ueber Indikationen und Erfolge der Tuberkulintherapie bei der kindlichen Tuberculose, publicada en Wiener klinische Wochenschrift, 1910; 23: 723-730) llamó la atención de Mantoux, sobre el hecho de que durante el tratamiento de la tuberculosis después de la inoculación subcutánea de tuberculina, en algunos enfermos de tuberculosis aparece una reacción inflamatoria en forma de eritema local y una pequeña 
inflamación. El 10-VIII-1908 presentó a la Academia de Ciencias de París sus resultados sobre la intradermorreacción tuberculínica que publicará dos años más tarde. Este informe supuso el gran punto de partida del diagnóstico de la tuberculosis. De forma sucinta, el autor describió la técnica de su intradermoreaction: introducir la tuberculina diluida en la superficie anterior de la nalga (la palabra rusa бедро hace referencia a la nalga, pero asimismo al muslo e, incluso, a las caderas), es imprescindible meter la aguja estrictamente bajo la piel. Para definir los resultados de la prueba, Mantoux consideró indispensable no sólo tener en cuenta las medidas de la pápula, sino también palparla. La máxima reacción aparece, según Mantoux, a las 48 horas. Comparó la pápula gráficamente a una escarapela y dirigió la atención a la posible aparición de una reacción general con fiebre de hasta 38 ó 39 grados centígrados. No deben considerarse los cambios que se producen en la zona de inoculación de la tuberculina al cabo de unas horas tras la inyección, "desaparecen casi siempre a los dos días, es entonces cuando la verdadera reacción, trascurrido ese tiempo, alcanza su máximo apogeo: no es posible confundirla con la prime$r a$ ". En conclusión, Mantoux afirmó: "tenemos la certeza de concluir que la reacción subcutánea, en comparación con la cutánea, es sencilla en su aplicación, completamente inocua, su mayor virtud es la exactitud y su gran sensibilidad". Dos meses después de su primera exposición, las comunicaciones de Mantoux se publicaron en forma de reseña en la revista Münchenere Medizinische Wochenschrift (1908, $\mathrm{n}^{\circ} 40$, pág. 2.116-2.117). Sin embargo, aquí se produjo una errata: se indicaba que la prueba subcutánea era una propuesta de Mantoux y Roux. En la recensión se hace notar la "peculiar sencillez" de esta reacción. Desde este momento comenzó a crecer la popularidad de la prueba de Mantoux ${ }^{12}$. Nuestro galeno estableció que con la edad aumenta la frecuencia de reacciones positivas y hacia los 15 años alcanza entre el $66-84 \%$ de positividad. En la siguiente comunicación, Mantoux señaló que durante la experimentación de la tuberculosis en cobayas la prueba intradérmica seguía dando positiva a los 19 días, mientras que la cutirreacción era negativa al cabo de ese tiempo. En 1910 publica un importante estudio en la prestigiosa revista de medicina francesa, Presse medicale, donde analizaba (junto con Aptekman y Macé de Lépinay) un total de 492 reacciones subcutáneas a la tuberculina, comparándolas con la prueba de Pirquet. En 428 casos coincidieron los resultados de ambas pruebas, pero en 64 casos frente a una reacción positiva clara de la prueba subcutá- nea, la cutánea resultó negativa. En este trabajo Mantoux reafirmó sus observaciones previas sobre la mayor sensibilidad de la prueba intradérmica en comparación con la de Pirquet ${ }^{13-16}$, desplazándola del diagnóstico clínico rutinario en toda Europa salvo en Noruega. Sin embargo, en realidad fue el médico alemán Felix Mendel el primero que la describió y por ello esta cutirreacción debería llamarse más justamente intradermorreacción de Mendel-Mantoux. Mendel había nacido el 2 de marzo de 1862 en Essen y murió el 19 de diciembre de 1925. Estudió en Bonn, Friburgo, Berlín y Marburgo. Se doctoró en Leipzig en 1884, y al año siguiente ejerció como médico general en Essen ${ }^{17-20}$. A él se debe la primera paratiroidectomía con éxito llevada a cabo en Viena en 1925 al extirpar un adenoma (Rudolph Virchow describió por vez primera las paratiroides humanas en 1863).

Sería Robert Koch, un genio en los métodos de tinción bacteriana (junto a Ferdinand Cohn, Paul Ehrlich y su azul de metileno, Friedrich Löeffler, Franz Ziehl y Friedrich Neelsen) quien aislaría el bacilo de la tuberculosis ${ }^{21}$ en la mítica fecha de 1882 (en este año, una ayudante de Koch, Frau Hesse, introduce el agar en los medios de cultivo). Más concretamente, Koch presentó sus resultados en el congreso de la Sociedad Fisiológica de Berlín el 24 de marzo de 1882. El camino estaba abonado por los experimentos previos de Jean Antoine Villemin, que ya en 1865 hablaba de un "virus" causal. En 1877, el año de nacimiento de Mantoux, Julius Conheim y Carl Salomonsen inocularon exudado tuberculoso en la cámara anterior del ojo del conejo, y Hermann E. von Tappeiner trasmitió por inhalación la tuberculosis en perros.

\section{LAS TUBERCULINAS}

Recordemos que en 1891 Robert Koch (18431910) había purificado su tuberculina vieja o antigua, OT (old tuberculin), a partir de cultivos filtrados estériles concentrados de $M$. tuberculosis de tipo humano. A partir de aquí preparaba un extracto con el medio de Edmond Nocard (en 1902 aislaría la cepa del M. Bovis usada para la BCG) y Emille Roux, a base de glicerina al 40 ó 50\%. A este remedio se le bautizó como "linfa o fluido de Koch", "Kochina” (algo cacofónico) o "Bacillinum” y, finalmente, "tuberculina”, que no consiguió alcanzar el status de vacuna. Koch inició el desarrollo de los medios de cultivo, usando suero bovino congelado, que luego Theobald Smith intentará sustituir por suero de perro hasta que 
Dorset impusiera en 1902 el huevo de gallina: con el agregado de otros nutrientes y de algunos inhibidores se llegaría al actual medio base de Löwenstein y Jensen (fosfato monopotásico, sulfato y citrato de magnesio, glicerol, asparragina, harina de papa y verde de malaquita) para el cultivo y aislamiento del bacilo tuberculoso.

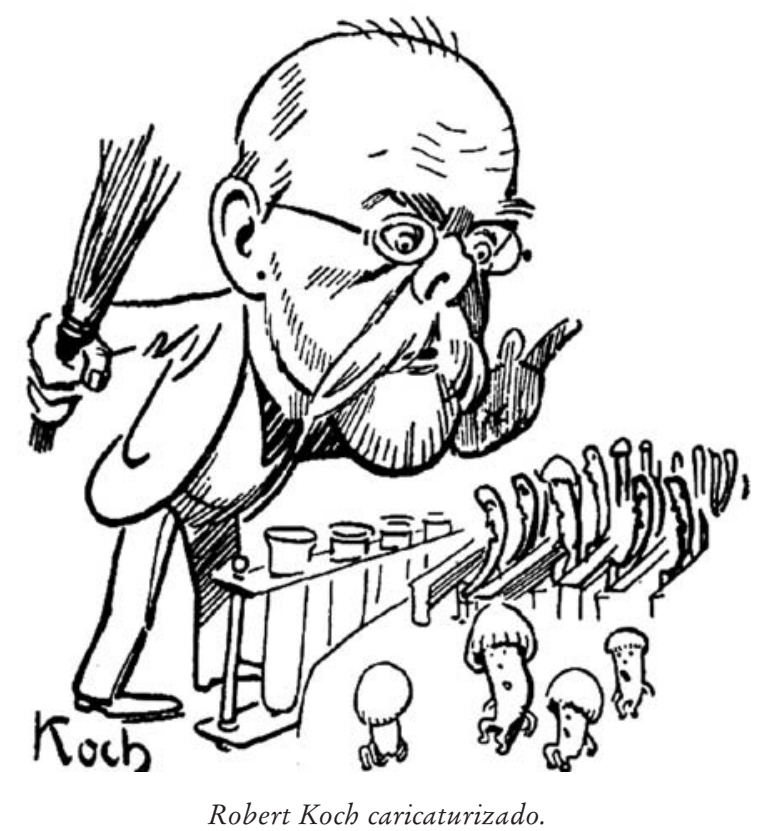

La OT de Koch (Premio Nobel de Medicina en 1905) inyectada subcutáneamente en enfermos tuberculosos podía producir una reacción cutánea. En 1932, la bioquímica americana Florence Barbara Seibert (1898-1991) del Instituto Henry Phipps de la Universidad de Pennsylvania en Philadelphia, purificó la OT de Koch mediante precipitación con sulfato amónico obteniendo un derivado proteico purificado, el conocido PPD (purified protein derivative). En 1939, M. A. Linnikova en la Unión Soviética produjo una PPD modificada (PPD-L), y en 1954 comenzó la producción a gran escala de PPD-L en dicho país. En 1941 Seibert y John Glenn de los laboratorios Mulford de la firma Merck Sharp and Dohme desarrollaron una cutirreacción tuberculínica con este PPD-S que sería adoptada como estándar por la OMS. Igualmente se deben a Seibert la implementación de normas de seguridad en la terapia de fármacos por vía IV, especialmente evitando la contaminación bacteriana del agua destilada para las soluciones de proteinas, y la asociación de ciertas bacterias con algunos tipos de cáncer. Ese mismo año 1941, Merrill Chase demuestra el papel de los linfocitos en la inmunidad antituberculosa ${ }^{22,19}$.

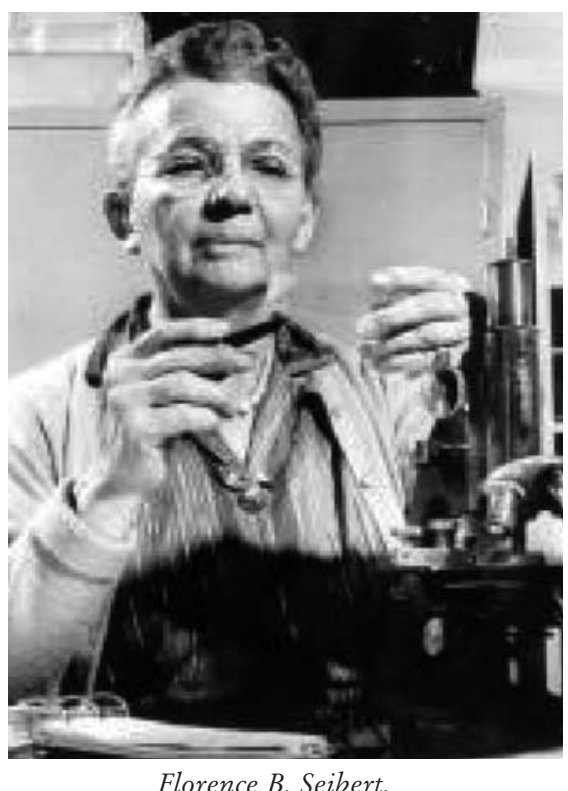

El inconveniente de este PPD-S radica en que carece de especificidad de especie micobacteriana al tratarse de un complejo de proteinas muy conservadas filogenéticamente. La FDA norteamericana ha probado el empleo del QuantiFERON-TB ${ }^{\circledR}$ de la firma Cellstis LTd para la cuantificación en horas a partir de sangre completa de infección tuberculosa latente, indicada para poblaciones de riesgo bajo o moderado.

La intradermorreacción de Mantoux orienta sobre la respuesta biológica frente al PPD que da lugar a un infiltrado inflamatorio. En el sitio de inoculación (cara volar del antebrazo) se lee el resultado de la prueba a las 72 horas de la inyección mediante la técnica de Sokal que mide en milímetros en el sentido transversal del antebrazo, el diámetro de la induración y no del eritema. Rinde falsos positivos en los casos de vacunación con BCG, sensibilidad cruzada con otras micobacterias, infecciones cutáneas, sesgos en la lectura o hipersensibilidad a los componentes del PPD. Resultados falsamente negativos pueden observarse más frecuentemente cuando existe anergia (término acuñado por Pirquet), infección reciente (menos de 8 a 12 semanas del contacto) o infección antigua. Aspectos todos ellos de indudable interés sanitario, significativamente en nuestro medio de trabajo ${ }^{23,24}$.

\section{AGRADECIMIENTOS}

Se agradece la colaboración para este artículo original de Karine Mantoux, Elena Ascensión Mazana y especialmente de Ricardo García Gómez por traducirnos manuscritos originales en ruso. 


\section{CORRESPONDENCIA}

javiermazana@telefonica.net

\section{REFERENCIAS BIBLIOGRÁFICAS}

1. Burke R M. An historical chronology of tuberculosis. Springfield, Ill: Charles C. Thomas, 2nd ed., 1955: 59-60.

2. Schott H. Crónica de la Medicina. Barcelona. Plaza \& Janés Editores, S. A., 1995. Tomo II: 369371.

3. Lebedeva ZA. Med Sestra. 1977; 36 (10): 51-2 Early diagnosis of tuberculosis (on the centenary of the birth of Charles Mantoux) (en ruso).

4. Vinnikov PL, Gerovits GA Charles Mantoux. Klin Med (Mosk). 1973; 51 (3): 144-6 (en ruso).

5. Korovkin V S I I. Mechnikov's role in the development of tuberculosis teachings. Probl Tuberk Bolezn Legk. 2004; (6): 60-4 (en ruso).

6. Mechnikov I I. Obras completas. Moscú, 1959, tomo 10, páginas 117-215.

7. Ledermann D W. La tuberculosis después del descubrimiento de Koch. Rev. chil. infectol., 2003; 20 supl.: 48-50.

8. Mazana J. La era precientífica de la infectología. Sobre el origen conceptual del contagio en la historia. Boletín de la Real Sociedad Económica de Amigos del País de Tenerife 2007. San Cristóbal de La Laguna 2008: 345-362.

9. Mantoux C. Intradermo-reaction de la tuberculine. Comptes rendus de l'Académie des sciences, Paris, 1908; 147: 355-357.

10. Mantoux C. La syphilis nerveuse latente et les stigmates nerveux de la syphilis. Paris, 1904.

11. Mazana J, Ariño M. Charles Robert Richet and some milestones in the history of allergies. Journal of Investigational Allergology and Clinical Immunology 1991; 1 (2): 93-100.
12. Báguena Cervellera M J. La tuberculosis y su historia. Fundación Uriach 1838. Colección Histórica de Ciencias de la Salud no 3. Barcelona, 1992.

13. Chauvet M. A centenary which has not kept all its promises: tuberculin. Rev Med Suisse Romande. 1990 Dec; 110 (12): 1067-70 (artículo en francés).

14. Beutner E H. Tuberculosis of the skin: historical perspectives on tuberculin and Bacille Calmette Guérin. Int J Dermatol. 1997; 36(1): 73-7.

15. Bothamley G H, Grange J M. The Koch phenomenon and delayed hypersensitivity: 1891-1991. Tubercle. 1991; 72 (1): 7-11.

16. Waddington $\mathrm{K}$. To stamp out "so terrible a malady": bovine tuberculosis and tuberculin testing in Britain, 1890-1939. Med Hist. 2004; 48 (1): 29-48.

17. Mendel F. Mendel-Mantoux test: En: Mendel F. Therapeutische Monatshefte, Berlin, 1903; 16: 177.

18. Mendel F. Die von Pirquet'sche Hautreaktion und die intravenöse Tuberkulinbehandlung. Medizinische Klinik, München, 1908; 4: 402-404.

19. Mendel F. Die Fibrolysinbehandlung und ihre Erfolge. Berlin, 1907.

20. Mendel F. Die Fortschritte der Salicylbehandlung bei rheumatischen Erkrankungen. Berlin, 1912.

21. Mazana J. Historia de la Inmunología. La búsqueda del yo frente al no yo. Alcalá de Henares: Río Henares Producciones Gráficas, S. L. 2002: 123-150. (edición no venal).

22. Mazana J. El programa de la Inmunología teórica y el nacimiento de la inmunopatología. Inmunología 1999; 18: 125-132.

23. Dirección General de Instituciones Penitenciarias. Programa de Prevención y Control de la Tuberculosis en el Medio Penitenciario. Madrid: Ediciones Díaz de Santos, S. A. Subdirección General de Sanidad Penitenciaria, 2001.

24. Plan para la prevención y control de la tuberculosis en España. Ministerio de Sanidad y Consumo, 15 de noviembre de 2007 (www.msc.es). 